1 Hacettepe Journal of Mathematics and Statistics

$\bigcap$ Volume 48 (3) (2019), 845-858

ReSEARCH ARTICLE

\title{
A New Defuzzification Method for Solving Fuzzy Mathematical Programming Problems
}

\author{
Amin Vahidi*† (D
}

\begin{abstract}
Solving a certain type of Fuzzy mathematical programming (FMP) require several steps and manual intervention in the solution process. Therefore, it reduces the optimality and increases the solving time. In this research, a methodology is pre-sented that, in addition to being applicable to all types of FMPs, increases optimali-ty and reduces the solving time. The proposed method generates improved solutions in less time and requires less monitoring during the problem-solving procedure.
\end{abstract}

Keywords: Linear programming, Fuzzy programming, Mathematical programming

Received : 23.10.2017 Accepted : 28.06.2018 Doi : 10.15672/HJMS.2018.612

\section{Introduction}

Fuzzy mathematical programming were developed to handle problems encoun-tered in real-world applications. The following list shows FMP applications are nu-merous and diverse [35]:

Agricultural economics:

- Analysis of water use in agriculture

- Farm structure optimization problem

- Regional resource allocation

- Water supply planning Assignment problems:

- Network location problem

Banking and finance:

- Capital asset pricing model

- Profit apportionment in concern

*School of Progress Engineering, Iran University of Science and Technology, Tehran, Iran, Email: amin.vahidi@gmail.com

$\dagger$ Corresponding Author. 
- Bank hedging decision

- project investment

- Environment management:

- Air pollution regulation problem

- Energy emission models

Manufacturing and production:

- Aggregate production planning problem

- machine optimization problems

- magnetic tape production

- optimal allocation of production of metal

- Optimal system design

- Crude oil manufacturing

- production-mix selection problem

- production scheduling

Personnel management:

- Coordination of personnel demand and available personnel structure

Transportation:

- Transportation problem

- Truck fleet

There are many types of FMPs, and specific methods are recommended for solv-ing each type. Bector and Chandra described these types and classification [4]. Also, there is no particular way to solve different FMP types. These diverse method mentioned by Lai and Hwang came in table 1 [26]. In addition, many of these methods require several steps[9], [42], [45] and manual intervention in the solving process[13],[12],[21],[17], [40], [28], [29], [20], [38] and [7]. Therefore, it reduces the optimization and increases the resolution time. In this research, a method has been proposed that, in addition to being applicable to all types of FMPs, increases the optimality and reduces the solving time. For more detailed difficulties and weaknesses of common methods and the proposed meth-od contribution to cover them see Comparison with the Common FMP Solving Methods section. FMP encompasses a wide array of methods [1],[15], [44]. The most convention-al form of a linear programming (LP) problem is formulated as follows:

$\max c x$

Subject to

$$
\begin{aligned}
a x & \leq b \\
x & \geq 0
\end{aligned}
$$

Where $x \in \mathbb{R}^{n}, c \in \mathbb{R}^{n}, b \in \mathbb{R}^{n}$ and $A \in \mathbb{R}^{m} \times \mathbb{R}^{n}$.

FMP problems can be generally classified into the following sub-classes[25], [24], [36], [47], [4]:

i. Linear programming problems with fuzzy inequalities and a crisp objective function,

ii. Linear programming problems with crisp inequalities and a fuzzy objective function,

iii. Linear programming problems with fuzzy inequalities and a fuzzy objective function,

iv. Linear programming problems with fuzzy resources and fuzzy coefficients, also termed linear programming problems with fuzzy parameters, where the components of $\mathrm{c}, \mathrm{b}$ and a are fuzzy numbers.

Alike the classification put forward by Bector and Chandra[4], Lai and Hwang[26], too, classified their solution methods in terms of the fuzzy parameter types. These methods 
may be used alongside the linear, nonlinear, integer and other types of conventional mathematical programming problem-solving methods.

Table 1. FMP problems types and solution methods

\begin{tabular}{|l|l|}
\hline Problem Condition & Solving Method \\
\hline \multirow{2}{*}{. Fuzzy $b$} & $1-1$ - Verdegay method [41] \\
\cline { 2 - 2 } & $1-2$ - Werners method [45] \\
\hline \multirow{3}{*}{ 2. Fuzzy $z, b$} & $2-1$ - Zimmermann method [48] \\
\cline { 2 - 2 } & 2 -2- Chanas method [9] \\
\cline { 2 - 2 } & 2-3- IFLP-1method [27] \\
\hline 3. Fuzzy c & 3-1- Verdegay method \\
\hline 4. Fuzzy $a$ or $b$, cor $a, b$ - $a, b, c$ & - Carlsson and Korhonen method [8] \\
\hline 5. Fuzzy $a, z$ or $a, b, z$ & -1- Lai \& Hwang method [26] \\
\hline 6. Expert Support System in Decision-making & 6-1- IFLP-II method [27] \\
\hline
\end{tabular}

Table 1 summarizes the primary FMP solution methodologies. Recently, Sakawa, Katagiri, and Matsui [37], presented an interactive two-level procedure that solves FLP problems similar to the works of Chanas [9], Verdegay [42] Werners [45] and Zimmermann [48]. Wan and Dong [43] introduced a methodology with trapezoi-dal fuzzy. Farhadinia [14] performed sensitivity analysis in linear programming problems with interval-valued trapezoidal fuzzy numbers similar to the works of Carlsson and Korhonen [8], Verdegay [42], [45], Zimmermann[48] and Chanas[9]. As evident from the tables, a number of recent FMP solution methodologies also come under the classification by Lai and Hwang [26]. In this work, we compare our proposed method with those given in Table 1. Some additional recent applications of FMP methodologies in practice are given in the works of [2], [3], [6], [10], [15], [18], [30], [31], [32], [33], [34]). This paper proposes a novel defuzzification method for solving FMP problems by using a large $M$ coefficient. Then this method applied to a vast variety of FMPs and compared with the common FMP solving methods. The proposed method exhibits superior performance over its counterparts by generating improved solu-tions in less time and requires less monitoring during the problem-solving procedure. In the conclusion, brief advantages of the proposed method and possible future researches are presented.

\section{Common Defuzzification Method}

Various FMP solving methodologies have been proposed to date and defuzzifica-tion is one of the most widely used. Defuzzification has numerous sub-types and is followed by conventional mathematical programming methods to yield the final solution. Here, a common defuzzification method given in[23] is used. Consider the following type of FMP problem:

$$
\begin{array}{r}
\max \sum c_{i} x_{i} \\
\text { Subject to } \\
(a x)_{i} \leq \tilde{b}_{i} \\
x_{i} \geq 0
\end{array}
$$

Where all values of $i, \tilde{b}_{i}$ are assumed fuzzy numbers and (2.1) could be given as the fuzzy inequality below: 


$$
\begin{array}{r}
\max \sum c_{i} x_{i} \\
\text { Subject to } \\
(a x)_{i} \geq \tilde{b}_{i} \\
x_{i} \geq 0
\end{array}
$$

(2.1) and (2.2) are the same provided membership functions of the fuzzy parame-ters and equalities for the two problems are equal. In common defuzzification methods[23], the FMP problem is solved in the follow-ing way:

2.1. Definition. For each $i, t_{i}$ there exists a crisp parameter that will replace the fuzzy parameter $\tilde{b}_{i}$ (i.e., defuzzification).

2.2. Definition. For each $i, \alpha^{+}$and $\alpha_{i}$ are the membership degrees of ti in the fuzzy $\tilde{b}_{i}$ number such that:

$$
\begin{aligned}
\alpha_{i}^{+} & =\frac{1}{\left(H T_{i}-L T_{i}\right)}\left(H T_{i}-t_{i}\right) \\
\alpha_{i}^{-} & =\frac{1}{\left(M T_{i}-L T_{i}\right)}\left(t_{i}-L T_{i}\right)
\end{aligned}
$$

Where $H T_{i}, M T_{i}$, and $L T_{i}$ are the upper bound, highest point and lower bound in the fuzzy number domain, respectively. See Figure 1.

Figure 1. Membership function

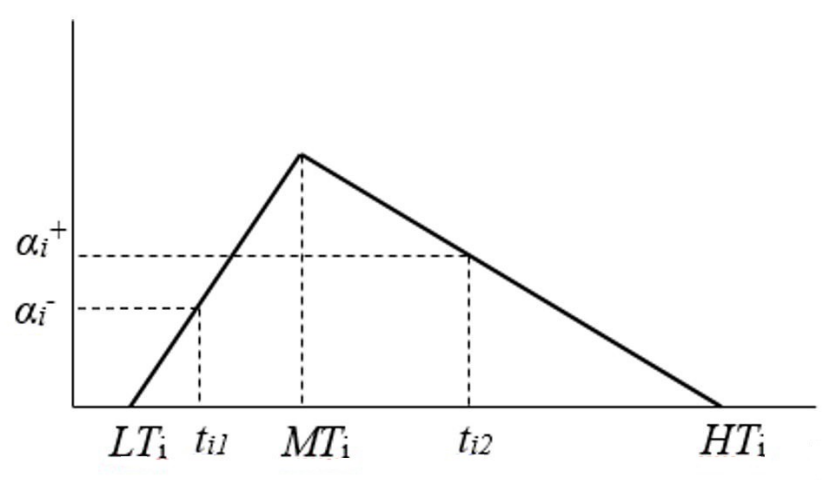

2.3. Definition. $h$ is the minimum membership degree of all fuzzy parameters $\left(\alpha_{i}^{ \pm} s\right)$ that are chosen based on the respective choice of ti. In other words, $h$ is the certainty level of the lower bound. The above formulation follows the concept of FMP as described by Zimmermann[49]. This formulation is in agreement with Bellman and Zadeh [5] in which the best set of solutions is found for the worst-case scenario with the goal and the 
constraints at maximum certainty levels. $h=\max \min \left[\alpha_{i}^{ \pm}\right]$:

$\max h$

Subject to

$(a x)_{i}=t_{i}$

$h \leq \alpha_{i}^{+}$

$h \leq \alpha_{i}^{-}$

$0 \leq h \leq 1$

$x_{i} \geq 0$

To solve P1, it should be first defuzzified and then, common mathematical pro-gramming methods such as simplex can be applied to solve the problem. The pro-posed method in this work is a revised version of the common methods and yields a better defuzzification method.

\section{The Proposed Method}

Consider the common method in [23] and its parameters. If $\mathrm{h}$ is assigned a large coefficient and the resulting statement is substituted into the objective function, improved results will be obtained, the description of which will be provided later. Following the naming convention for the big M method used for solving prob-lems with "greater-than" or "less-than" constraints, the new coefficient is also named M. Coefficient M should be large enough to impose searching for the big-gest (optimal) $h$ that is possible. The amount of $\mathrm{M}$ is described in the following sec-tions. In addition, the proposed method gives the option to trade-off between $\mathrm{h}$ and $\mathrm{Z}$. In this situation, we could reduce $\mathrm{M}$ by a certain amount, so we could reach a solution by a certain amount of lesser $\mathrm{h}$ but better Z

$$
\begin{array}{r}
\max \left(M h+\sum c_{i} x_{i}\right) \\
\text { Subject to } \\
(a x)_{i}=t_{i} \\
h \leq \alpha_{i}^{+} \\
h \leq \alpha_{i}^{-} \\
0 \leq h \leq 1 \\
x_{i} \geq 0
\end{array}
$$

By employing this method and applying a few modifications to it, many types of FMP problems will be handled. In this method, the defuzzification and solving phases are carried out simultaneously. The remainder of the paper is dedicated to the comparison of this method to common defuzzification methods also the pri-mary FMP solving methods.

3.1. Notes. If a or c is fuzzy this proposed method could be applied in the same way de-scribed above.

\section{Comparison with the Common Defuzzification Method}

4.1. Proposition. In the above conditions, $h$ values are equal but the objective function in the pro-posed method has either superior or, in its least, equal performance than common defuzzification methods. 
Proof. If many solutions yield the same $\mathrm{h}\left(\alpha_{i}^{0}\right.$ and $\left.\alpha_{i}^{*}\right)$, the common method (twophase method) will select one of the solutions $\left(\alpha_{i}^{0}\right)$ indifferently followed by problem de-fuzzification. Then, in the second phase, the method will find a solution for the problem. On the other hand, if there exists a solution in the first phase such that a different defuzzified problem is yield with a better solution $\left(\alpha_{i}^{*}\right)$, the proposed method chose this one $\left(\alpha_{i}^{*}\right)$ and results in an improved solution.

\begin{tabular}{|l|l|l|}
\hline Values/Methods & $\begin{array}{l}\text { Common Defuzzifica-tion } \\
\text { Method }\end{array}$ & $\begin{array}{l}\text { Proposed Defuzzification } \\
\text { Method }\end{array}$ \\
\hline $\mathrm{h}$ value & \multicolumn{2}{|c|}{$h=\min \alpha_{i}^{0}=\min \alpha_{i}^{*}(\mathrm{~h}$ are equal in both methods $)$} \\
\hline$\alpha_{i}$ values & $\alpha_{i}^{0}$ & $\alpha_{i}^{*}$ \\
\hline$t_{i}$ Values & $t_{i}^{0}($ as Definition 2$)$ & $t_{i}^{*}($ as Definition 2$)$ \\
\hline$x$ crisp formulas & $a x=t_{i}^{0}$ & $a x=t_{i}^{*}$ \\
\hline$x$ optimal Val-ues & $x_{i}^{0}$ & $x_{i}^{*}$ \\
\hline$z$ optimal Value & $z^{0}=\sum c_{i} x_{i}^{0}$ & $z^{*}=\sum c_{i} x_{i}^{*}$ \\
\hline Comparison & \multicolumn{2}{|c|}{$z^{0} \leq z^{*}$} \\
\hline
\end{tabular}

4.2. Example. Consider the assumptions in Proposition 4.1 for the following example.

$$
\begin{array}{r}
\max X_{1}+5 X_{2} \\
X_{1}-X_{2} \leq \tilde{b}_{1} \\
X_{1}+3 X_{2} \geq \tilde{b}_{2} \\
X_{1}, X_{2} \geq 0
\end{array}
$$

Where the fuzzy parameters are as follows

$$
\begin{aligned}
& \alpha_{1}^{+}=-0.02 t 1+2.4 \\
& \alpha_{1}^{-}=0.04 t 1-3 \\
& \alpha_{2}^{+}=-0.01 t 2+2.3 \\
& \alpha_{2}^{-}=0.05 t 2-5
\end{aligned}
$$

The following results are obtained for the given problem coded in GAMS 23.3 and solved by the CPELX solver

The two-phase method- Phase 1:

\begin{tabular}{|c|}
\hline Result \\
\hline VARIABLE X1.L $=95.500$ \\
VARIABLE X2.L $=5.500$ \\
VARIABLE h.L $=0.600$ \\
VARIABLE t1.L $=90.000$ \\
VARIABLE t2.L $=112.000$ \\
VARIABLE a1l.L $=0.600$ \\
VARIABLE a1h.L $=0.600$ \\
VARIABLE a2l.L $=0.600$ \\
VARIABLE a2h.L $=1.180$ \\
\\
TIME $=0.031$ SECONDS \\
\hline
\end{tabular}


The two-phase method - Phase 2 (replacing $t_{1}$ by 90 and $t_{2}$ by 112):

\begin{tabular}{|l|}
\hline \multicolumn{1}{|c|}{ Result } \\
\hline VARIABLE X1.L $=95.500$ \\
VARIABLE X2.L $=5.500$ \\
VARIABLE z.L $=123.000$ \\
EXECUTION TIME $=0.000$ SEC- \\
ONDS \\
\hline
\end{tabular}

The proposed one-phase method:

\begin{tabular}{|l|}
\hline \multicolumn{1}{|c|}{ Result } \\
\hline VARIABLE X1.L $=110.000$ \\
VARIABLE X2.L $=20.000$ \\
VARIABLE obj.L $=210.000$ \\
VARIABLE h.L $=0.600$ \\
VARIABLE t1.L $=90.000$ \\
VARIABLE t2.L $=170.000$ \\
VARIABLE a1l.L $=0.600$ \\
VARIABLE a1h.L $=0.600$ \\
VARIABLE a2l.L $=3.500$ \\
VARIABLE a2h.L $=0.600$ \\
EXECUTION TIME $=0.000$ SEC- \\
ONDS \\
\hline
\end{tabular}

The above example displays the statement in Proposition 4.1. Here, $x_{1}$ and $x_{2}$ are different but $\mathrm{h}$ is the same in both methods. Moreover, the $\alpha_{i}^{ \pm} \mathrm{s}$ and the determinant of $\mathrm{h}$ value are different whereas $\mathrm{h}$ itself is equal to 0.6 in both cases. It is evident from the above example that with different objective values, the proposed method leads to nearly 70 percent improvement in the value of the objective function. It is worth noting that the processing time of the proposed method is shorter. It is negligibly small compared to the total processing time of the two-phase method that is 0.031 seconds. In addition, a trade-off can be achieved between membership degree and optimality in the one-phase method while the two-phase method seeks to increase the membership degree anyway. Moreover, it leads to loss of a great proportion of the objective function. In other words, a trade-off can be achieved in the one-phase method between optimality of $h$ and optimality of $\sum c_{i} x_{i}$ by varying coefficient $m$.

4.3. Proposition. Consider the case where a decision-maker prefers losing certainty by $h_{0}$ to gain optimality by $z_{0}$. This preference is taken into account in the solution process if $M$ is set to be less (more) than $z_{0}\left(h_{0}\right)$, and if the problem is a maximization problem (minimization).

Proof. Suppose there exists a solution in which a change of $\triangle z$ in the objective function and a change of $-\triangle h$ in certainty levels are observed. The total objective function is then changed by:

$$
M \triangle h+\triangle z
$$


This solution is selected when the below expression is positive (negative) and if the problem is maximization (minimization).

$$
-M \triangle h+\triangle z \geq 0 \Rightarrow M \leq \triangle z / \triangle h
$$

\begin{tabular}{|l|l|l|}
\hline Values/Methods & $\begin{array}{l}\text { Common Defuzzifica-tion } \\
\text { Method }\end{array}$ & $\begin{array}{l}\text { Proposed Defuzzification } \\
\text { Method }\end{array}$ \\
\hline $\mathrm{h}$ value & $h^{1}=\min \alpha_{i}^{1}=h$ & $h^{2}=\min \alpha_{i}^{2}=h-h_{0}$ \\
\hline$\alpha_{i}$ values & $\alpha_{i}^{1}$ & $\alpha_{i}^{2}$ \\
\hline$t_{i}$ Values & $t_{i}^{1}($ as Definition 2$)$ & $t_{i}^{2}($ as Definition 2$)$ \\
\hline$x$ crisp formulas & $a x=t_{i}^{1}$ & $a x=t_{i}^{2}$ \\
\hline$x$ optimal Val-ues & $x_{i}^{1}$ & $x_{i}^{2}$ \\
\hline$z$ optimal Value & $z^{1}=\sum c_{i} x_{i}^{1}$ & $z^{2}=\sum c_{i} x_{i}^{2} \geq z^{1}+z^{0}$ \\
\hline Comparison & \multicolumn{2}{|c|}{$h^{1} \geq h^{2} \mathrm{but}^{1} \leq z^{2}$} \\
\hline
\end{tabular}

Proposition 4.3 is described in the following example.

4.4. Example. Consider the above assumptions for the following example.

$$
\begin{aligned}
\max 4 X 1 & +X 2 \\
4 X_{1}-X_{2} & \geq 300 \\
5 X_{1}-X_{2} & \leq 1800 \\
X_{2} & \leq \tilde{b}_{1} \\
X_{1}, X_{2} & \geq 0
\end{aligned}
$$

Where the fuzzy parameters are as follows

$$
\begin{aligned}
& \alpha_{1}^{+}=-0.0005 * t 2+0.86 \\
& \alpha_{1}^{-}=1
\end{aligned}
$$

The following results are obtained for the given problem coded in GAMS 23.3 and solved by the CPELX solver.

\begin{tabular}{|l|}
\hline \multicolumn{1}{|c|}{ Result } \\
\hline VARIABLE X1.L $=360.000$ \\
VARIABLE X2.L $=0.000$ \\
VARIABLE obj.L $=1440.000$ \\
VARIABLE h.L $=0.860$ \\
VARIABLE t1.L $=0.000$ \\
VARIABLE a1h.L $=0.860$ \\
EXECUTION TIME $=0.000$ SEC- \\
ONDS \\
\hline
\end{tabular}

A value of $M=100000$ can be interpreted as infinite and given this value of $\mathrm{M}$; we wish to increase parameter $\mathrm{h}$ as great a value as possible. By setting $M$ to1000, we have preferred one unit of membership degree to 1000 units of $\sum c_{i} x_{i}$. Therefore, if there exists an alternative solution with more than 1000 units of $\sum c_{i} x_{i}$ such that the value of $\mathrm{h}$ is reduced by 1 or less, it would be the solu-tion of choice. However, not many solutions exist for $M=1000$ and the results are therefore the same. For instance, reducing $M$ to 
even a value of 400 results in the failure of the solu-tion. However, a different solution is yielded if we set $M$ to 399 . In other words, the different solution leads to the above preference.

\begin{tabular}{|l|}
\hline \multicolumn{1}{|c|}{ Result } \\
\hline VARIABLE X1.L $=233.333$ \\
VARIABLE X2.L $=633.333$ \\
VARIABLE obj.L $=1566.667$ \\
VARIABLE h.L $=0.543$ \\
VARIABLE t1.L $=633.333$ \\
VARIABLE a1h.L $=0.543$ \\
EXECUTION TIME $=0.000$ SEC- \\
ONDS \\
\hline
\end{tabular}

Performing the following calculations shows that the above conditions for obtain-ing an alternative solution are satisfied.

$$
\begin{aligned}
\triangle z & =1566.667-1440.000=126.667, \triangle h=0.860-0.543=0.317, \\
\triangle z / \triangle h & =399.580, M=399<399.580
\end{aligned}
$$

\section{Comparison with the Common FMP solving Methods}

In this section advantages of the proposed method in comparison with the com-mon methods for different types of problems and their corresponding solution methods (Table 1) are discussed.

First': The proposed method is applicable to a wide area of FMP problems so it is comprehensive. This method eliminates the need for using different solution methods for different FMP problems, as mentioned earlier in the literature review section. Even more recent researches [13], [12], [21] , [16], [40], [28], [29], [19], [38], [7] could only be applied to a particular sub-type of a given problem with particular condi-tions, such as equality constraint and etc.

Second: The proposed method improves solution objective function compared to the two-phase defuzzification methods. Because in the two-phase method the problem is defuzzified first, so a certain degree of certainty is chosen for solving. Therefore, objective function optimality is sought. In the common methods, a fixed value (degree of satisfaction) is assigned to the certainty level. As described above, in the process some better solution may be omitted in phase one. Therefore, in the common methods, this is possible that bet-ter value of the objective function is missed. A number of such methods are pro-posed in[9], [42], [45] [48].

Third: The proposed method has the ability to achieve a trade-off between cer-tainty and optimality as previously described. This type of trade-off is not present-ed in existing methods. The emphasize in these methods has been on the paramet-ric solutions in sensitivity analyses that make trade-off a difficult task to achieve. The methods of [45], [9] and [48] target certainty maximization without considering the loss of optimality. Methods such as [42], [39] created a table for achieving a trade-off between cer-tainty and optimality. However, a number of difficulties were still present:

- Manual intervention was required to achieve the trade-off,

- Increasing the number of $\alpha$ (certainty degree) levels leads to a more precise final solution, but a a longer time is needed. An increase in the number of certainty 
levels makes manual decision-making a more complicated task for the decisionmakers.

- The proposed method yields equal or superior solutions, Irrespective of the number of certainty levels intended for creating the table. The advantage of the proposed method could be explained by its search for optimality in continues solution space. Decision-making in the other methods takes place in a discrete solution space.

Fourth: Most of the common methods assign the same parameter $(\alpha)$ to all S. Therefore, It creates a smaller solution space and leading to a reduced value of $\mathrm{h}$ or/and $\mathrm{z}$ as a consequence. Examples of such methods (as given in Table 1) are the following:

- Fuzzy $b$ Verdegay [41] method

- Fuzzy $z, b$ Zimmermann [48] method

- Fuzzy $c$ Solving dual problem by Fuzzy b method

- Fuzzy $a, b, c$ - Carlsson and Korhonen[8] method

5.1. Proposition. . The common methods that assign the same value to all $\alpha_{i} s$ cause the solution space becomes successively smaller when the number of constraints increases.

Proof. Suppose two fuzzy parameters $\tilde{b}_{1}$ and $\tilde{b}_{2} . \alpha_{1}$ determine $h\left(a_{1}\right.$ is equal or less than $a_{2}$ ) and $a_{2}$ could have any value equal or greater than $a_{1}$. By employing this constraint, $a_{2}$ will be fixed to a single value and the problem solution space will lessen. Moreover, there may be no feasible solution. The following example provides further description of the issue.

\begin{tabular}{|l|l|l|}
\hline Values/Methods & \multicolumn{1}{|l|}{$\begin{array}{l}\text { Common FMP solv- } \\
\text { ing Methods }\end{array}$} & $\begin{array}{l}\text { Proposed Defuzzifi- } \\
\text { cation Method }\end{array}$ \\
\hline$h$ value & \multicolumn{2}{|l|}{$h=\min \alpha_{i}^{0}=\min \alpha_{i}^{*}(\mathrm{~h}$ are equal in both methods $)$} \\
\hline$\alpha_{i}$ value & $\alpha_{i}^{0}$ (all $\alpha_{i}^{0}$ s are equal) & $\alpha_{i}^{*}$ \\
\hline$t_{i}$ Values & $t_{i}^{0}($ as Definition 2$)$ & $t_{i}^{*}$ (as Definition 2$)$ \\
\hline$x$ crisp formulas & $a x=t_{i}^{0}$ & $a x=t_{i}^{*}$ \\
\hline$x$ optimal Values & $x_{i}^{0}$ & $x_{i}^{*}$ \\
\hline$z$ optimal Value & $z_{0}=\sum c_{i} x_{i}^{0}$ & $z^{*}=\sum c_{i} x_{i}^{*}$ \\
\hline Comparison & \multicolumn{2}{|c|}{$z^{0} \leq z^{*}$} \\
\hline
\end{tabular}

5.2. Example. Consider the above assumptions (i.e., setting all $a_{i} s$ equal) for the following example.

$$
\begin{array}{r}
\max 5 X 1+X 2 \\
X 1-X 2=\tilde{b}_{1} \\
X 1+3 X 2=\tilde{b}_{2} \\
X 1 \geq \tilde{b}_{3} \\
X 1, X 2 \geq 0
\end{array}
$$


Where the $\mathrm{c}$ is as follows

$$
\begin{aligned}
& \alpha_{1}^{+}=-0.02 * t 1+2.4 \\
& \alpha_{1}^{-}=1 \\
& \alpha_{2}^{+}=1 \\
& \alpha_{2}^{-}=0.05 * t 2-5 \\
& \alpha_{3}^{+}=1 \\
& \alpha_{3}^{-}=0.04 * t 3-4.4
\end{aligned}
$$

The following results are obtained for the given problem coded in GAMS 23.3 and solved by the CPELX solver.

The common methods (setting all $a_{i} s$ equal):

\begin{tabular}{|l|}
\hline \multicolumn{1}{|c|}{ Result } \\
\hline VARIABLE X1.L $=111.613$ \\
VARIABLE X2.L $=5.161$ \\
VARIABLE obj.L $=563.226$ \\
VARIABLE $\mathrm{h} . \mathrm{L}=0.065$ \\
VARIABLE t1.L $=116.774$ \\
VARIABLE t2.L $=101.290$ \\
VARIABLE t3.L $=111.613$ \\
VARIABLE a1h.L $=0.065$ \\
VARIABLE a2l.L $=0.065$ \\
VARIABLE a3l.L $=0.065$ \\
EXECUTION TIME $=0.000$ SEC- \\
ONDS \\
\hline
\end{tabular}

The proposed method:

\begin{tabular}{|l|}
\hline \multicolumn{1}{|c|}{ Result } \\
\hline VARIABLE X1.L $=113.333$ \\
VARIABLE X2.L $=0.000$ \\
VARIABLE obj.L $=566.667$ \\
VARIABLE h.L $=0.133$ \\
VARIABLE t1.L $=113.333$ \\
VARIABLE t2.L $=113.333$ \\
VARIABLE t3.L $=113.333$ \\
VARIABLE a1h.L $=0.133$ \\
VARIABLE a2l.L $=0.667$ \\
VARIABLE a31.L $=0.133$ \\
EXECUTION TIME $=0.000$ SEC- \\
ONDS \\
\hline
\end{tabular}


As explained above, the example shows that the proposed method increases the value of the objective function slightly and almost doubles the certainty level. In more complicated problems that some equality or other restrictive constraint is in place, even the common methods may not lead to a feasible solution while the proposed method will do. Fifth: In many methods, the fuzzy numbers should be in a particular form to make the method capable of solving the problem. For example, If the fuzzy numbers are two-sided, we have $\alpha_{I}^{-}$and $\alpha_{J}^{+}$and if all $\alpha_{I}^{ \pm} \mathrm{S}$ is same, there will be no solution.

Sixth: Some of the methods [8] solve the problem parametrically, thus, take a longer time to complete and require manual control during the solution process.

Seventh: $z_{0}$ and $z_{1}$ (the maximum and minimum values of the objective function due to fuzzy parameters, respectively) in methods such as[42], [45] and [48] or $p_{0}$ and $b_{0}$ (the slope and the initial point) in methods such as [9] should be determined prior to problem-solving. This issue makes problem-solving more difficult and causes loss of better solutions as mentioned above.

Eighth: A number of methods such as[42], [22] perform discrete decision-making. These methods provide tables that represent discrete solutions, their least membership degree and objective functions. However, there may be better solutions between the two discrete decision points. In addition, the decision-maker should manually select one of the determined solutions.

\section{Conclusion}

FMP is classified into different types based on the diversity of its solution methods and fuzzy number forms [11], [14], [16], [13], [43], [46] . In this paper, we proposed a novel FMP solution methodology intended for application to all types of FMPs. The proposed methodology has a number of distinct advantages over the already existing common FMP methodologies; this is a comprehensive method that ena-bles application of the proposed method to all types of FMP problems (i.e., differ-ent methods and fuzzy number forms), generation of superior, faster and more optimal solutions due to a continuous solution space, computerized, faster and more precise trade-off between certainty and optimality otherwise not attainable in the existing methods, obtaining feasible solutions in certain problems for which the common methods return no solution, reduced processing time and no need for manual control of the solution process given the non-parametric nature of the solu-tion.

\section{References}

[1] Attari H. and Nasseri S. H. , New Concepts of Feasibility and Efficiency of Solutions in Fuzzy Mathematical Programming Problems, Fuzzy Inf. Eng., vol. 6, no. 2, pp. 203221, Jun. 2014.

[2] Azadeh A., Moghaddam M. ,Khakzad M., and Ebrahimipour V., A flexible neural networkfuzzy mathematical programming algorithm for improvement of oil price es-timation and forecasting, Comput. Ind. Eng., vol. 62, no. 2, pp. 421430, 2012.

[3] Azadeh A., Saberi M., Asadzadeh S. M., and Khakestani M., A hybrid fuzzy mathe-matical programming-design of experiment framework for improvement of energy consumption estimation with small data sets and uncertainty: The cases of USA, Can-ada, Singapore, Pakistan and Iran, Energy, vol. 36, no. 12, pp. 69816992, 2011.

[4] Bector C. R. and Chandra S., Fuzzy Mathematical Programming and Fuzzy Matrix Games. Springer, 2005.

[5] Bellman R. and Zadeh L. A., Decision Making in a Fuzzy Environment, Manage. Sci., vol. 17, pp. 141164, 1970. 
[6] BilgenB., Application of fuzzy mathematical programming approach to the produc-tion allocation and distribution supply chain network problem, Expert Syst. Appl., vol. 37, no. 6, pp. 44884495, 2010.

[7] Biswas A., and Modak N., A Multiobjective Fuzzy Chance Constrained Programming Model for Land Allocation in Agricultural Sector: A case study, vol. 10. 2017.

[8] Carlsson C., and Korhonen P., A Parametric Approach to Fuzzy Linear Programming, Fuzzy Sets Syst., vol. 20, no. 1, pp. 1730, 1986.

[9] Chanas S., The Use of Parametric Programming in Fuzzy Linear Programming, Fuzzy Sets Syst., vol. 11, no. 13, pp. 229241, 1983.

[10] Cheng C. B,. and Cheng C. J., Available-to-promise based bidding decision by fuzzy mathematical programming and genetic algorithm, Comput. Ind. Eng., vol. 61, no. 4, pp. 9931002, 2011.

[11] Ebrahimnejad A., Tavana M., Lotfi F. H., Shahverdi R., and Yousefpour M., A three-stage Data Envelopment Analysis model with application to banking industry, Meas-urement, vol. 49, pp. 308319, 2014.

[12] Effati S., Pakdaman M., and Ranjbar M., A new fuzzy neural network model for solv-ing fuzzy linear programming problems and its applications, Neural Comput. Appl., vol. 20, no. 8, pp. 12851294, 2011.

[13] Ezzati R., Khorram E., and Enayati R., A new algorithm to solve fully fuzzy linear programming problems using the MOLP problem, Appl. Math. Model., Mar. 2013.

[14] Farhadinia B., Sensitivity analysis in interval-valued trapezoidal fuzzy number linear programming problems, Appl. Math. Model., vol. 38, no. 1, pp. 5062, Jan. 2014.

[15] Fazlollahtabar H., Mahdavi I., and Mohajeri A., Applying fuzzy mathematical pro-gramming approach to optimize a multiple supply network in uncertain condition with comparative analysis, Appl. Soft Comput., vol. 13, no. 1, pp. 550562, Jan. 2013.

[16] Figueroa-García J. C., Chalco-Cano Y., and Román-Florez H., Distance measures for Interval Type-2 fuzzy numbers, Discret. Appl. Math., Dec. 2014.

[17] Figueroa-García J. C., Kalenatic D., and Bello C. A. L., An iterative algorithm for fuzzy mixed production planning based on the cumulative membership function, Ingeniería, vol. 16, no. 2, pp. 617, Dec. 2011.

[18] Gupta P., Mehlawat M. K., and Saxena A., Asset portfolio optimization using fuzzy mathematical programming, Inf. Sci. (Ny)., vol. 178, no. 6, pp. 17341755, 2008.

[19] Inuiguchi M., and Ichihashi H., Relative modalities and their use in possibilistic linear programming, Fuzzy Sets Syst., vol. 35, no. 3, pp. 303323, 1990.

[20] Inuiguchi M., Ichihashi H., and Kume Y., Relationships between modality con-strained programming problems and various fuzzy mathematical programming prob-lems, Fuzzy Sets Syst., vol. 49, no. 3, pp. 243259, 1992.

[21] Javadian N., Maali Y., and Mahdavi-Amiri N., Fuzzy linear programming with grades of satisfaction in constraints, Iran. J. Fuzzy Syst., vol. 6, no. 3, pp. 1735, 2009.

[22] Kamyad A. V., Hassanzadeh N., and Chaji J., A New Vision on Solving of Fuzzy Linear Programming, in 2009 International Conference on Computational Intelligence and Software Engineering, 2009, pp. 14.

[23] Kikuchi S., A method to defuzzify the fuzzy number: transportation problem applica-tion, Fuzzy Sets Syst., vol. 116, no. 1, pp. 39, 2000.

[24] Kumar A., Appadoo S. S., and Bector C. R., A note on Generalized fuzzy linear programming for decision making under uncertainty: Feasibility of fuzzy solutions and solving approach, Inf. Sci. (Ny)., vol. 266, pp. 226227, May 2014.

[25] Kumar A., and Kaur J., General Form of Linear Programming Problems with Fuzzy Parameters, J. Appl. Res. Technol., vol. 11, no. 5, pp. 629635, Apr. 2013.

[26] Lai Y. J., and Ching-L C.L., Hwang, Fuzzy mathematical programming: methods and applications. Springer Verlag, 1992.

[27] Lai Y. J., and Hwang C. L., IFLP-II: A decision support system, Fuzzy Sets Syst., vol. 54, no. 1, pp. 4756, Feb. 1993.

[28] León T., Liern V., Ruiz J. L., and Sirvent I., A fuzzy mathematical programming ap-proach to the assessment of efficiency with DEA models, Fuzzy Sets Syst., vol. 139, no. 2, pp. 407419, 2003. 
[29] Maeda T., Fuzzy linear programming problems as bi-criteria optimization problems, Appl. Math. Comput., vol. 120, no. 13, pp. 109121, 2001.

[30] MitraK. , Gudi D. R., Patwardhan C. S., and Sardar G., Towards resilient supply chains: Uncertainty analysis using fuzzy mathematical programming, Chem. Eng. Res. Des., vol. 87, pp. 967981, 2009.

[31] Mula J., Peidro D., and Poler R., The effectiveness of a fuzzy mathematical program-ming approach for supply chain production planning with fuzzy demand, in Interna-tional Journal of Production Economics, 2010, vol. 128, no. 1, pp. 136143.

[32] Mula J., Poler R., García-Sabater G. S., and F. C. Lario, Models for production plan-ning under uncertainty: A review, Int. J. Prod. Econ., vol. 103, no. 1, pp. 271285, 2006.

[33] Pishvaee M. S., and Razmi J., Environmental supply chain network design using multi-objective fuzzy mathematical programming, Appl. Math. Model., vol. 36, no. 8, pp. 34333446, 2012.

[34] Pishvaee M. S., Razmi J., and S. A. Torabi, Robust possibilistic programming for socially responsible supply chain network design: A new approach, Fuzzy Sets Syst., vol. 206, pp. $120,2012$.

[35] Rommelfanger H., Fuzzy linear programming and applications, Eur. J. Oper. Res., vol. 92, no. 3, pp. 512527, 1996.

[36] Saberi-Najafi H., and Edalatpanah S. A., A note on A new method for solving fully fuzzy linear programming problems, Appl. Math. Model., vol. 37, no. 1415, pp. 78657867, Aug. 2013.

[37] Sakawa M., Katagiri H., and Matsui T., Interactive fuzzy random two-level linear programming through fractile criterion optimization, Math. Comput. Model., vol. 54, no. 11, pp. 31533163, 2011.

[38] Shaocheng T., Interval number and fuzzy number linear programmings, Fuzzy Sets Syst., vol. 66, no. 3, pp. 301306, 1994

[39] Taghizadeh K., Bagherpour M., and Mahdavi I., Application of fuzzy multi-objective linear programming model in a multi-period multi-product production planning prob-lem, Int. J. Comput. Intell. Syst., vol. 4, no. 2, 2011.

[40] Vasant P. M., Solving Fuzzy Linear Programming Problems With Modified S-Curve Membership Function, Int. J. Uncertainty, Fuzziness Knowledge-Based Syst., vol. 13, no. 1, pp. 97109, Feb. 2005.

[41] Verdegay J. L., Fuzzy mathematical programming, Fuzzy Inf. Decis. Process., vol. 231, p. 237, 1982.

[42] Verdegay J. L., A dual approach to solve the fuzzy linear programming problem, Fuzzy Sets Syst., vol. 14, no. 2, pp. 131141, 1984.

[43] Wan S.P., and Dong J.Y., Possibility linear programming with trapezoidal fuzzy numbers, Appl. Math. Model., vol. 38, no. 56, pp. 16601672, Mar. 2014.

[44] Wan S.P., and Dong J.Y., Interval-valued intuitionistic fuzzy mathematical pro-gramming method for hybrid multi-criteria group decision making with interval-valued intuitionistic fuzzy truth degrees, Inf. Fusion, Feb. 2015.

[45] Werners B., An interactive fuzzy programming system, Fuzzy Sets Syst., vol. 23, no. 1, pp. 131147, 1987.

[46] Zhang F., Ignatius J., Lim C. P., and Zhao Y., A new method for ranking fuzzy numbers and its application to group decision making, Appl. Math. Model., vol. 38, no. 4, pp. 15631582, Feb. 2014

[47] Zhu B., and Xu Z., A fuzzy linear programming method for group decision making with additive reciprocal fuzzy preference relations, Fuzzy Sets Syst., vol. 246, pp. 1933, Jul. 2014.

[48] Zimmermann H. J., Fuzzy programming and linear programming with several objec-tive functions, Fuzzy Sets Syst., vol. 1, no. 1, pp. 4555, 1978.

[49] Zimmermann H. J., Fuzzy Set Theory and Its Applications. 2001. 